

Whole-genome phylogenies of the family Bacillaceae and expansion of the sigma factor gene family in the Bacillus cereus species-group

Schmidt et al. 


\title{
Whole-genome phylogenies of the family Bacillaceae and expansion of the sigma factor gene family in the Bacillus cereus species-group
}

\author{
Timothy R Schmidt, Edgar J Scott II and David W Dyer
}

\begin{abstract}
Background: The Bacillus cereus sensu lato group consists of six species (B. anthracis, B. cereus, B. mycoides, B. pseudomycoides, $B$. thuringiensis, and $B$. weihenstephanensis). While classical microbial taxonomy proposed these organisms as distinct species, newer molecular phylogenies and comparative genome sequencing suggests that these organisms should be classified as a single species (thus, we will refer to these organisms collectively as the $B C$ species-group). How do we account for the underlying similarity of these phenotypically diverse microbes? It has been established for some time that the most rapidly evolving and evolutionarily flexible portions of the bacterial genome are regulatory sequences and transcriptional networks. Other studies have suggested that the sigma factor gene family of these organisms has diverged and expanded significantly relative to their ancestors; sigma factors are those portions of the bacterial transcriptional apparatus that control RNA polymerase recognition for promoter selection. Thus, examining sigma factor divergence in these organisms would concurrently examine both regulatory sequences and transcriptional networks important for divergence. We began this examination by comparison to the sigma factor gene set of $B$. subtilis.

Results: Phylogenetic analysis of the $B c$ species-group utilizing 157 single-copy genes of the family Bacillaceae suggests that several taxonomic revisions of the genus Bacillus should be considered. Within the $B C$ species-group there is little indication that the currently recognized species form related sub-groupings, suggesting that they are members of the same species. The sigma factor gene family encoded by the Bc species-group appears to be the result of a dynamic gene-duplication and gene-loss process that in previous analyses underestimated the true heterogeneity of the sigma factor content in the BC species-group.

Conclusions: Expansion of the sigma factor gene family appears to have preferentially occurred within the extracytoplasmic function (ECF) sigma factor genes, while the primary alternative (PA) sigma factor genes are, in general, highly conserved with those found in $B$. subtilis. Divergence of the sigma-controlled transcriptional regulons among various members of the $B C$ species-group likely has a major role in explaining the diversity of phenotypic characteristics seen in members of the $B C$ species-group.
\end{abstract}

\section{Background}

The genus Bacillus consists of a heterogeneous group of Gram-positive heterotrophic aerobic or facultative anaerobic bacilli with the ability to form environmentally resistant, metabolically inert spores [1]. These soil-borne organisms are ubiquitous throughout the world, and occupy surprisingly diverse environments $[2,3]$. Within this large genus, the B. cereus sensu lato group consists

\footnotetext{
* Correspondence: david-dyer@ouhsc.edu

Department of Microbiology and Immunology, Oklahoma University Health Sciences Center, Oklahoma City, OK 73117 USA
}

of six species [B. anthracis $(B a), B$. cereus $(B c), B$. mycoides, B. pseudomycoides, B. thuringiensis (Bt), and $B$. weihenstephanensis], based on classical microbial taxonomy [4]. However, newer molecular phylogenies and comparative genome sequencing suggests that these organisms should be classified as a single species [5]. On the surface, this conclusion seems difficult to reconcile with the varied biological characteristics of these organisms. Some $B c$ strains are thermophiles [6], while B. weihenstephanensis is psychrophilic [7]. By contrast, many members of this group are mesophiles, and can be
C Biomed Central

C 2011 Schmidt et al; licensee BioMed Central Ltd. This is an Open Access article distributed under the terms of the Creative Commons Attribution License (http://creativecommons.org/licenses/by/2.0), which permits unrestricted use, distribution, and reproduction in any medium, provided the original work is properly cited. 
found in a variety of locales including soil, on plant surfaces and in the mammalian gastrointestinal microflora [8]. Some members of this group appear to be nonpathogenic, while others cause diverse diseases including gastroenteritis, food poisoning [8], endophthalmitis [9], tissue abscesses $[10,11]$, and anthrax [2]. Bt strains have the capacity to cause disease in insects $[12,13]$ and possibly nematodes [14-16], while some evidence suggests that $B c$ strains are part of the normal insect gut flora $[8,17]$. Nevertheless, whole genome comparisons between these organisms reveal a surprising similarity in gene content, and Han et al. [18] have concluded "that differential regulation [of gene content] modulates virulence rather than simple acquisition of virulence factor genes", a conclusion confirmed by other studies [19]. Consequently, we will refer to these organisms as the $B c$ species-group, to reflect the extremely close phylogenetic relationships between these organisms.

How do we account for the underlying genomic similarity of these phenotypically diverse microbes? It has been established for some time that the most rapidly evolving and evolutionarily flexible portions of the bacterial genome are regulatory sequences and transcriptional networks [20-22]. Thus, it is no surprise that major differences between $B c$ species-group organisms reside in the regulation of gene expression rather than gene content. A prime example of this divergence is the PlcR-PapR quorum-sensing operon, present in all $B c$ species-group organisms, but harboring point mutations that differentiate group members from one another $[23,24]$. The papR locus encodes a quorum-sensing signal (a secreted peptide) that is internalized and binds to PlcR, a transcriptional activator that controls gene expression and is important for $B c$ virulence. There are four distinct phylogenetic groups of the PapR peptide, each with point mutations that result in a unique quorum-sensing 'pherotype' [23]. The PlcR sensor in each pherotype has co-evolved to exclusively bind only its cognate PapR peptide, and each PlcR pherotype is consequently 'blind' to the quorum sensing signals secreted by other $B c$ pherotypes. $B a$ strains (and a low percentage of $B c$ strains) [24] have taken PlcR-PapR divergence a step further. These organisms carry a unique nonsense mutation in PlcR that inactivates the quorum-sensing function entirely. Since PlcR and the global virulence regulator AtxA on the virulence plasmid pXO1 appear to antagonize one another [24], PlcR inactivation after $B a$ acquired pXO1 appears necessary for full virulence of $B a$.

This is not to say that horizontal gene transfer and genome reduction have not been important in remodeling genomes within the $B c$ species-group. For instance, the virulence plasmids pXO1 and pXO2 in $\mathrm{Ba}$ appear to have been acquired by horizontal gene transfer [25], and represent $52 \%$ of the unique coding capacity found in the $B a$ genome. Although these genes have a significant impact on the $B a$ pathogenic phenotype, this plasmid gene content comprises only 176 genes, representing a small fraction of the total coding capacity of the $B a$ genome. Genome reduction has played a modest role in divergence of the $B c$ species-group [26], likely being responsible for the reduced genome size of $B c$ NVH39198. However, genome reduction is probably more important for speciation events; e.g., the M. leprae genome is fully $26 \%$ smaller than that of M. tuberculosis, and carries over 1100 pseudogenes with functional orthologs in M. tuberculosis. GR has essentially eliminated $50 \%$ of the coding capacity of the $M$. leprae genome [27]. Thus, subtler genome alterations within the $B c$ species-group, such as gene duplication, divergence and point mutations probably have contributed as much or more than horizontal gene transfer and genome reduction to the unique niche adaptations of individuals within the $B c$ species-group.

Anderson et al. [28] first noted that the genomes of $B c$ species-group organisms appeared to harbor an overabundance of sigma factors, compared to B. subtilis strain 168. Bacterial sigma factors bind RNA polymerase and allow the holoenzyme to recognize promoter sequences 5 ' to the site of initiation of transcription [29]. Typically, bacteria encode several different sigma factors, each of which is responsible for controlling a suite of genes by activating transcription at a unique set of sigma factor specific promoter sequences. Sigma factors generally belong to two primary categories, the sigma $^{54}$ and the sigma ${ }^{70}$ families [29]. The sigma ${ }^{54}$ proteins encoded by the $B c$ species-group are very highly conserved, and ubiquitously present as a single copy gene. Therefore, a phylogenetic analysis of these proteins in the $B c$ species-group was not particularly revealing (data not shown). We consequently focused further efforts on the sigma ${ }^{70}$ proteins. Sigma ${ }^{70}$ proteins can be further differentiated into primary alternative (PA) sigma factors and extracytoplasmic function sigma factors (ECF) [30]. In general, PA sigma factors control expression of many housekeeping functions of the cell (e.g., B. subtilis SigA), and allow the organism to respond to specific environmental stimuli such as heatshock (e.g., SigB) [31,32]; in B. subtilis, several PA sigma factors are integral to the sporulation developmental pathway $[33,34]$. ECF sigma factors typically activate gene expression in response to extracellular signals such as the availability of specific iron sources $[35,36]$ and commonly are essential for disease pathogenesis [37-39]. The activity of a PA or (more commonly) an ECF sigma is often controlled by an anti-sigma factor that renders the sigma factor in a state unable to bind RNA polymerase. Activation of the sigma factor for RNA polymerase 
binding and transcription initiation is triggered by a signal (ligand binding, covalent modification or proteolysis) that inactivates the anti-sigma factor [40].

Thus, sigma factors activate transcription in response to environmental or developmental signals, and selectively activate transcription by recognizing different consensus promoter sequences to tailor gene expression to those signals [41]. This suggested to us that many of the phenotypic differences between members of the $B c$ species-group organisms might be a consequence of the sigma factor gene expansion [28], accompanied by divergence among the sigma factor regulons of these organisms. Consequently, we began to explore the phylogeny of the sigma factors found in various $B c$ species-group members, by comparison to the experimentally wellunderstood model organism $B$. subtilis. To place these studies in context, we began by constructing a phylogeny of the Bacillaceae using whole-genome single copy genes. This phylogeny suggested that the current taxonomic affiliation of many members of the Bacillaceae should be reconsidered. Using this phylogeny as a basis, we then examined the phylogenetic relationships of the sigma factors encoded by members of the $B c$ speciesgroup. We find that the overabundance of sigma factors encoded by the $B c$ species-group organisms is specifically in the ECF sigma factors, rather than in the sigma factor group as a whole. The sigma factor gene family encoded by the $B c$ species-group is the end-product of a dynamic gene-duplication and gene-loss process that has, until now, underestimated the true heterogeneity of ECF sigma factor content in the $B c$ species-group. Further, the sigma factor content carried by any given member of the $B c$ species-group suggests that both shared and unique gene expression patterns have evolved during the divergence of this group of organisms from a common ancestor.

\section{Results and Discussion}

\section{Whole-genome single copy-gene phylogeny of the} family Bacillaceae

Phylogenetic analysis of 157 single copy genes (Additional file 1) of 41 Bacillaceae genomes (Table 1), using Paenibacillus and Brevibacillus as outgroups, indicate that there are five main lineages and suggest four modifications to the taxonomy of the family (Figure 1). The initial divergence within the Bacillaceae was between Exiguobacterium, an aerobic, asporogenous, and irregularly shaped Gram-positive bacterium recently linked to bacteraemia [42], and the bulk of the family. Subsequent to this, B. halodurans, B. clausii, B. selenitireducens, and $B$. pseudofirmus (the $B$. halodurans group) diverged from the rest of the family, followed by the divergence of Oceanobacillus and Lysinibacillus. Within the remaining Bacillus genera, there is a multichotomous split between the $B$. subtilis group (including B. subtilis, $B$. amyloliquefaciens, $B$. licheniformis, and B. pumilus), the $B c$ species-group, $B$. megaterium, and a group that includes strains of Geobacillus and Anoxybacillus (G. kaustophilus, G. thermodenitrificans, Geobacillus WCH70, and Anoxybacillus flavithermus). Although results from the maximum likelihood analysis indicate a lack of resolution between these four groups, the inclusion of Geobacillus and Anoxybacillus within Bacillus has strong support (particularly relative to the B. halodurans group). This indicates that Oceanobacillus, Lysinibacillus, Geobacillus, and Anoxybacillus are more closely related to some Bacillus spp. than are members of the $B$. halodurans group, and that, if one wishes the taxonomy of the group to reflect evolutionary history, should be subsumed within Bacillus.

These relationships are significantly different than those deduced by most other strategies, until recently. The family Bacillaceae, including the genus Bacillus, is a heterogeneous collection of gram-positive rod-shaped bacteria within the Firmicutes and includes both freeliving and pathogenic species with a world-wide distribution. Their heterogeneity is reflected in a highly variable $\mathrm{GC}$ content ranging between 33 and $78 \% \mathrm{G}$ + C. To date, the most commonly utilized phylogenetic strategy for examining these phylogenetic relationships has utilized rDNA sequences. Xu and Cote [43], for example, identified 10 groups within Bacillaceae on the basis of $16 \mathrm{~S}-23 \mathrm{~S}$ internal transcribed spacer sequences. Seven of those groups included members of the genus Bacillus. The ribosomal database project (RDB) [44] currently includes 13,359 sequences for members of Bacillaceae (as of 10/01/2010). However, recent study of relationships of members of Bacillus has begun to look beyond 16S rDNA sequences and has benefitted from the many whole-genome sequences becoming available. For example, Alcaraz et al. [45] examined twenty Bacillus genomes and, utilizing a core-genome conceptual data analysis, determined the phylogeny of known Bacillus spp. included in their study and identified four main lineages. Although their study employed different outgroups, methods, and genomes sampled, their conclusions were similar to ours and consistent with the idea that the taxonomic affiliation of these organisms needs to be reconsidered, in the light of whole-genome analyses. This is not to suggest that phylogenetic analyses based on $16 \mathrm{~S}$ rDNA sequence should be supplanted by whole genome analyses, due to the obvious practical limitations of requiring the entire genome sequence of an isolate prior to phylogenetic analysis. However, whole genome phylogenetic methods such as that presented here, and by other groups such as Alcaraz et al. [45] indicate that the resolution of $16 \mathrm{~S}$ phylogenies should be viewed 
Table 1 Genome sequences used in this study

\begin{tabular}{|c|c|c|c|c|}
\hline Organism & Locus tag & Size (bp) & Source of isolation & Accession \\
\hline Anoxybacillus flavithermus WK1 & Aflv & 2846746 & Geothermal waste-water drain & NC_011567 \\
\hline Exiguobacterium AT1b & EAT1B & 2999895 & Yellowstone Nat'l Park & NC_012673 \\
\hline Exiguobacterium sibiricum 255-15 & Exig & 3040786 & Siberian permafrost & NC_010556 \\
\hline Geobacillus WCH70 & GWCH70 & 3508804 & Wood chip composter heap & NC_012793 \\
\hline Bacillus selenitireducens MLS10 & Bsel & 3592487 & Axonic lake mud & NC_014219 \\
\hline Geobacillus kaustophilus HTA426 & GK & 3592666 & Deep-sea sediment & NC_006510 \\
\hline Geobacillus thermodenitrificans NG80-2 & GTNG & 3608012 & Deep oil reservoir & NC_009328 \\
\hline Oceanobacillus iheyensis HTE831 & OB & 3630528 & Deep-sea sediment & NC_004193 \\
\hline Geobacillus C56-T3 & GC56T3 & 3650813 & Hot spring & NC_014206 \\
\hline Geobacillus Y412MC61 & GYMC61 & 3667901 & Hot spring & NC_013411 \\
\hline Bacillus pumilus SAFR-032 & BPUM & 3704465 & JPL spacecraft assembly facility & NC_009848 \\
\hline Bacillus amyloliquefaciens FZB42 & RBAM & 3918589 & soil & NC_009725 \\
\hline Bacillus cereus cytotoxis NVH 391-98 & Bcer98 & 4094159 & Food poisoning outbreak & NC_009674 \\
\hline Bacillus halodurans C-125 & $\mathrm{BH}$ & 4202352 & Deep-sea sediment & NC_002570 \\
\hline Bacillus subtilis 168 & BSU & 4215606 & Model organism & NC_000964 \\
\hline Bacillus licheniformis ATCC-14580 & $\mathrm{BL}$ & 4222597 & soil & NC_006270 \\
\hline Bacillus licheniformis DSM-13 & Bli & 4222645 & soil & NC_006322 \\
\hline Bacillus pseudofirmus OF4 & BpOF4 & 4249248 & soil & NC_013791 \\
\hline Bacillus clausii KSM-K16 & $A B C$ & 4303871 & soil & NC_006582 \\
\hline Lysinibacillus sphaericus C3-41 & Bsph & 4817463 & soil & NC_010382 \\
\hline Bacillus megaterium DSM319 & BMD & 5097447 & soil & NC_014103 \\
\hline Bacillus anthracis Ames & BA & 5227293 & Bovine carcass & NC_003997 \\
\hline Bacillus cereus $03 \mathrm{BB} 102$ & $\mathrm{BCA}$ & 5228663 & Human blood isolate & NC_012472 \\
\hline Bacillus thuringiensis Al-Hakam & BALH & 5313030 & Iraq bioweapons facility & NC_008600 \\
\hline Bacillus thuringiensis konkukian & BT & 5314794 & Human tissue necrosis & NC_005957 \\
\hline Bacillus cereus biovar anthracis $\mathrm{Cl}$ & $\mathrm{BACl}$ & 5419036 & Chimpanzee carcass & NC_014335 \\
\hline Bacillus cereus B4264 & $\mathrm{BCB}$ & 5427083 & Bloodstream isolate from pneumonia patient & NC_011725 \\
\hline Bacillus cereus ATCC 14579 & $\mathrm{BC}$ & 5432652 & Dairy product & NC_004722 \\
\hline Bacillus cereus AH187 & BCAH187 & 5449308 & Food poisoning isolate & NC_011658 \\
\hline Bacillus anthracis str Sterne & BAS & 5486649 & Vaccine strain & NC_005945 \\
\hline Bacillus anthracis A0248 & BAA & 5503926 & Human disease & NC_012659 \\
\hline Bacillus anthracis Ames-0581 & GBAA & 5503926 & Bovine carcass & NC_007530 \\
\hline Bacillus cereus Q1 & $\mathrm{BCQ}$ & 5506207 & Deep oil reservoir & NC_011969 \\
\hline Bacillus anthracis CDC 684 & BAMEG & 5506763 & $N A^{*}$ & NC_012581 \\
\hline Bacillus megaterium QM-B1551 & $\mathrm{BMQ}$ & 5523192 & soil & NC_014019 \\
\hline Bacillus cereus ATCC-10987 & BCE & 5588834 & Cheese spoilage & NC_003909 \\
\hline Bacillus cereus AH820 & BCAH820 & 5599857 & Human periodontitis & NC_011773 \\
\hline Bacillus thuringiensis BMB171 & $\mathrm{BMB}$ & 5643051 & soil & NC_014171 \\
\hline Bacillus cereus G9842 & BCG & 5736823 & Stool sample from food poisoning outbreak & NC_011772 \\
\hline Bacillus cereus ZK & $\mathrm{BCZK}$ & 5843235 & Zebra carcass & NC_006274 \\
\hline Bacillus weihenstephanensis KBAB4 & KBAB & 5872743 & soil & NC_010184 \\
\hline
\end{tabular}

* NA: not available

with caution. Our results also are consistent with the conclusions of Tourasse et al. [46], who have recently described an extremely robust analysis of this group of organisms using a combination of MSLT, AFLP and MLEE genotyping. Again, these methodologies have the advantage of not requiring whole genome sequence for analysis. Nevertheless, the comprehensive nature of using whole genome sequences for phylogenetic comparisons is attractive due to the power of the technique, when the data is available.

Within the $B c$ species-group (Figure 2), $B c$ subsp. cytotoxis NVH 391-98 is the most distantly related of the $B c$ species-group, followed by $B$. weihenstephanensis. The remaining $B C$ strains form a paraphyletic assemblage that excludes $B$. thuringiensis and $B$. anthracis. While both the gene content and extent of divergence suggest 


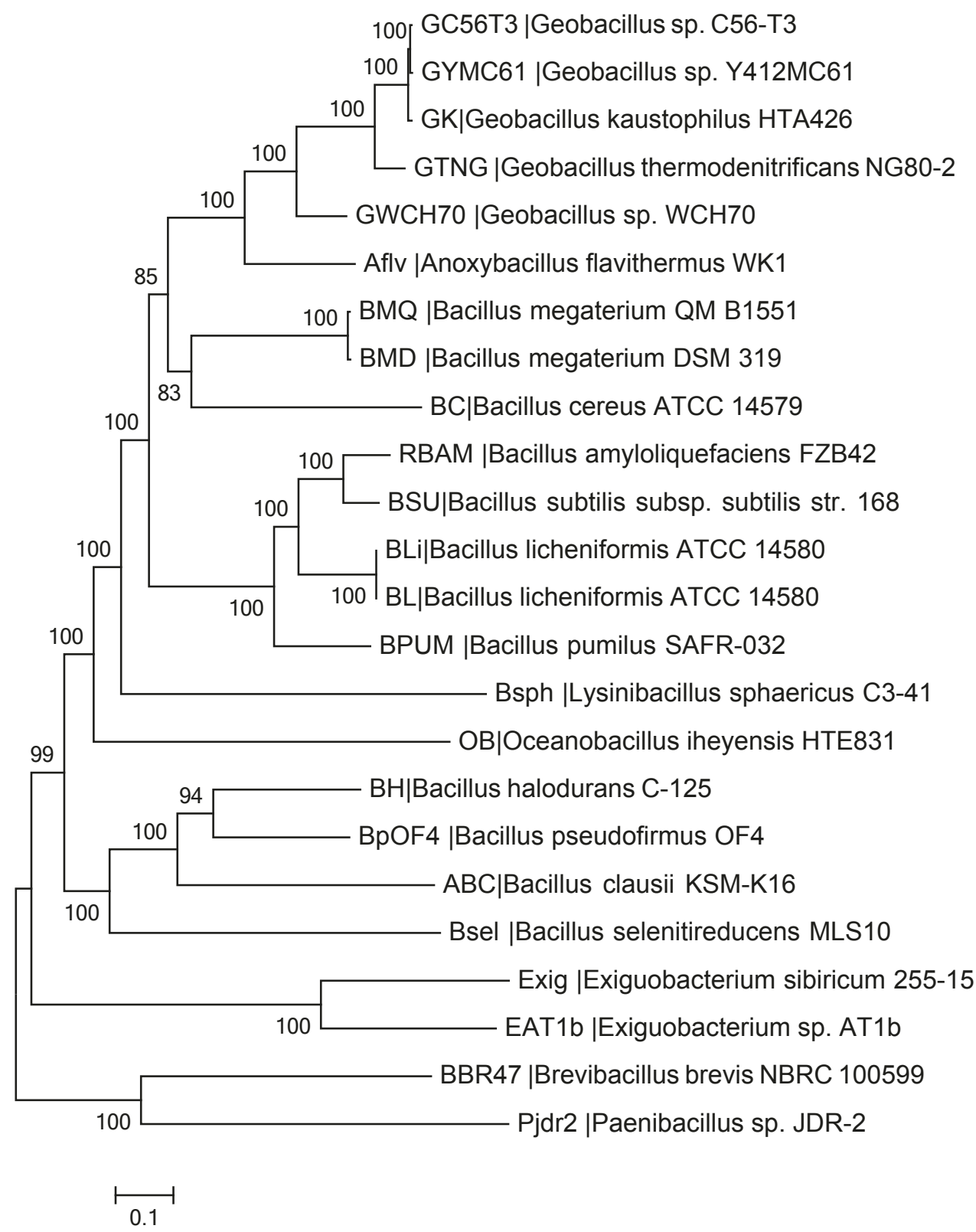

Figure 1 Whole genome single-copy gene phylogeny of the family Bacillaceae and the Bc species-group. Relationships among members of the family Bacillaceae based on the results obtained from a maximum-likelihood analysis of 157 single-copy genes found in each of the 43 genomes included in the analysis, using the genomes of Paenibacillus JDR-2 and Brevibacillus brevis NBRC-100599 to root the analysis. Numbers along the internodes are the number of times that node was supported in 100 bootstrap replicates. This is a phylogram that displays the relationships of all of the Bacillaceae; the legend denotes substitutions per nucleotide.

that Bc subsp. cytotoxis and perhaps B. weihenstephanensis may warrant specific recognition, other organisms within the $B c$ species-group do not. For example, the three $B t$ strains did not group together. $B t$ Konkukian is most closely related to $B a$, while the other two $B t$ strains are more distantly related. The closest relative of $B t \mathrm{Al}$ Hakam is $B c$ 03BB102, while $B t$ strain BMB171 is mostly nearly related to $B c$ strain ATCC14579. Preliminary results for two other $B t$ strains, kurstaki
T03a001 and HD1, also fall within this region of the phylogeny (data not shown). $B a$ strains form a monophyletic lineage and could be a sub-species of $B c$. While subsuming $B a$ and $B t$ within $B c$ may be problematic, there are definitively $B c$ strains (e.g. $B c$ AH820) that are significantly more closely related to $B a$ or $B t$ than they are to other strains of $B c$. Thus, our phylogenetic assessment is consistent with other recent suggestions that the $B c$ group exhibits sufficiently high genetic similarity that 


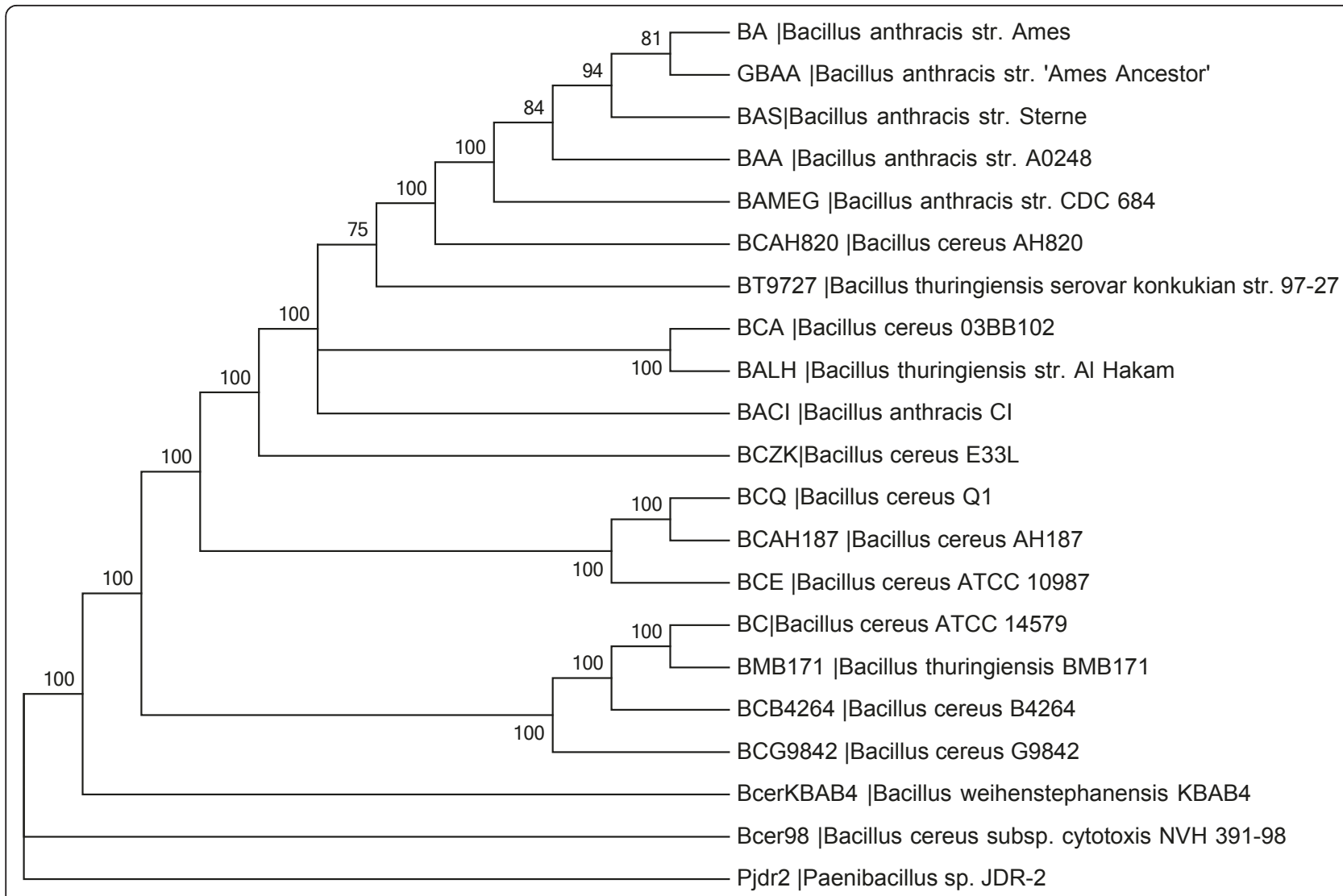

Figure 2 Whole-genome single-copy gene phylogeny of the Bc-species group. This analysis was performed as for Figure. 1, except that as the relationships between members of the $B C$ species-group were not resolved by this maximum iikelihood analysis (data not shown), Figure 2 is a cladogram that more clearly delineates the relationships within the $B C$ species-group.

these organisms could be members of a single species $([5,47-49])$.

\section{Expansion of the sigma factor gene family in the $B C$ species-group of the Bacillaceae Initial dataset containing the Bc species-group sigma factors}

Iterative BLAST searches initiated from 18 B. subtilis sigma factors initially identified 515 potential sigma factors within the 20 strains of $B c$ species-group genomes (see Additional file 2). A total of 16 genes identified in the iterative BLAST searches were excluded from the final analysis due to either their short length (in some cases producing non-overlapping genes when aligned with all other sigma factor homologs), and/or lack of evidence from the Multiple Expectation Maximization for Motif Elicitation (MEME) analysis warranting their inclusion as a sigma factor (see below). TBLASTN searches to the nucleotide sequences of the $B c$ speciesgroup identified 3 additional non-annotated sigma factors that are orthologs of BSU13450 (SigI - present in the BCAH187 B. cereus genome), and BAS5102 and
BAS1035 (both present in the B. thuringiensis AlHakam genome), respectively.

The seven most informative motifs from MEME analysis proved useful in segregating functional sigma factors from sequences that bore superficial similarity to sigma factors (false positives), and allowed us to differentiate PA sigma factors from ECF sigma factors (Tables 2 and 3, also see Additional file 3 for the complete MEME results). Comparing these MEME motifs to previously identified regions of sequence conservation among sigma factors [50] also was informative. Motifs 1 and 5, which are located near or slightly to the N-terminal side of the -35 and -10 promoter binding sites (sigma factor regions 4 and 2), respectively, were present in most sigma factors. MEME motifs 2 and 7 also were identified within region 2 (the -10 binding site), and differentiate PA from ECF sigma factors. MEME motifs 3 and 6 are at the -35 binding site and are also representative of PA and ECF sigma factors, respectively. MEME motif 4 , lying to the $\mathrm{N}$-terminal region of the -10 binding site, is largely restricted to PA sigma factors but is also present in 2 ECF sigma factor paralogs. Aside from 
Table 2 MEME motifs found in PA sigma factors

\begin{tabular}{ccccccccc}
\hline PA Locus Tag & 1 & 2 & 3 & 4 & 5 & 6 & 7 & Orthologous BSU locus tag \\
\hline BAS4194 & + & + & + & + & + & & BSU25200 (SigA) \\
BAS0928 & + & + & + & + & + & & BSU04730 (SigB) \\
& + & + & + & + & & BSU16470 (SigD) \\
BAS3755 & + & + & + & + & + & & BSU15320 (SigE) \\
BAS3983 & + & + & + & + & + & & BSU23450 (Sig) \\
BAS3754 & + & + & + & + & + & & BSU15330 (SigG) \\
BAS0093 & + & & & + & & BSU00980 (SigH) \\
BAS3231 & & + & & + & & BSU13450(Sigl) \\
BAS4236 & + & + & + & + & + & & BSU25760, 26390 (SigK) \\
BAS3522 & & & & & & BSU12560 (Xpf) \\
BAS3823 & + & + & & + & \\
BAS5102 & + & + & & + & \\
Bcer98_2607 & + & + & & & \\
BCG9842_0035 & + & + & + & + & + & \\
BMB171_P0077 & + & + & + & + &
\end{tabular}

A ' + ' designates the presence of a motif in the PA sigma factor gene at the left. MEME motifs are presented here for a representative (from the BAS genome where available) genome for each of the PA sigma factors detected by the analyses.

the well-documented differences in size between ECF and PA sigma factors, these data suggest that the principle functional difference between the two is directly associated with the binding of the protein to DNA recognition sites.

\section{Sigma factor genes in the Bacillaceae}

Taken as a whole, the number of PA sigma factor genes found within the genomes of the Bacillaceae was roughly independent of the genome sizes of these organisms (Figure 3). By contrast, the numbers of ECF sigma factor genes found in the Bacillaceae increased in direct proportion to genome size. Thus, the overabundance of sigma factor genes earlier observed in the $B c$ speciesgroup organisms [28] resulted from a preferential expansion in the ECF sigma factors, compared to the PA sigma factor genes. This might indicate that members of the $B C$ species-group have evolved a more sophisticated ability to sense and respond transcriptionally to extracellular signals, compared to other members of the Bacillaceae with smaller genomes and a relative paucity of ECF sigma factor genes. Alternatively, this may indicate that other regulatory regimes (e.g., twocomponent regulators) are preferentially used by members of the Bacillaceae with smaller genomes, for coordinating transcription with extracellular signals. Further work is necessary to differentiate between these possibilities.

Phylogenetic analysis of the BC species-group sigma factors Within the $B c$ species-group, phylogenetic analysis of the sigma factors of the $B c$ species-group identified 41 paralogous sigma factor genes in these organisms (Tables 4, 5, and 6, Additional files 2 and 4). Any one
Table 3 MEME motifs found in ECF sigma factors

\begin{tabular}{|c|c|c|c|c|c|c|}
\hline ECF Locus Tag & 123 & $\begin{array}{ll}3 & 4\end{array}$ & 5 & 6 & 7 & $\overline{\text { Orthologous BSU locus tag }}$ \\
\hline BAS0964 & + & & & + & + & \\
\hline BAS2285 & + & + & + & & + & \\
\hline \multirow[t]{7}{*}{ BAS3082 } & + & & & + & + & BSU09520 (SigM) \\
\hline & + & & + & + & + & BSU27120 (SigV) \\
\hline & + & & + & + & + & BSU01730 (SigW) \\
\hline & + & & + & + & + & BSU23100 (SigX) \\
\hline & + & & + & + & + & BSU38700 (SigY) \\
\hline & + & & + & + & + & BSU26840 (SigZ) \\
\hline & + & & + & + & + & BSU14730 (YlaC) \\
\hline BAS0171 & + & & & + & + & \\
\hline BAS0613 & + & & + & & + & \\
\hline BAS1035 & + & & + & + & + & \\
\hline BAS1626 & & & + & & + & \\
\hline BAS1658 & + & & + & + & + & \\
\hline BAS1966 & + & & + & + & & \\
\hline BAS2323 & + & & + & + & + & \\
\hline BAS2545 & + & & + & & + & \\
\hline BAS2600 & & & + & + & + & \\
\hline BAS2758 & + & & + & + & + & \\
\hline BAS3383 & & & + & + & + & \\
\hline BAS4558 & + & & + & + & + & \\
\hline BAS5212 & + & & + & + & + & \\
\hline BALH_4199 & + & & + & + & + & \\
\hline BCAH187_A3458 & & + & + & & & \\
\hline BCAH820_1326 & & & & & + & \\
\hline BCE_1118 & + & & + & + & + & \\
\hline BCE_5322 & & & + & + & + & \\
\hline Bcer98_3970 & & & + & & + & \\
\hline BcerKBAB4_3133 & + & & + & & & \\
\hline BcerKBAB4_4716 & + & & + & + & + & \\
\hline BcerKBAB4_5577 & + & & + & + & & \\
\hline BCQ_1681 & & & + & & + & \\
\hline
\end{tabular}

$A$ ' + ' designates the presence of a motif in the ECF sigma factor gene at the left. MEME motifs are presented here for a representative (from the BAS genome where available; otherwise as the locus tag indicates) gene for each of the ECF sigma factors detected by the analyses.

genome contained at most 27 sigma factor genes, hinting at an extensive history of gene duplication and loss in these lineages. Of these 41 genes, 14 were PA sigma factors and 27 were ECF sigma factors. Four of the PA sigma factors genes and 21 ECF sigma factor genes were unique to the $B c$ species-group, indicating that the majority of sigma factor gene expansion within the $B c$ species-group is concentrated on the ECF sigma factor genes, as noted above. By comparison, 18 sigma factor genes were found for B. subtilis, 10 of which were PA sigma factors. The $B c$ species-group harbors 9 PA sigma factors that are orthologous to the more extensively studied sigma factors of $B$. subtilis and appear to be the most evolutionarily conserved. (Six of these PA sigma factors appear to be very highly conserved as they were 


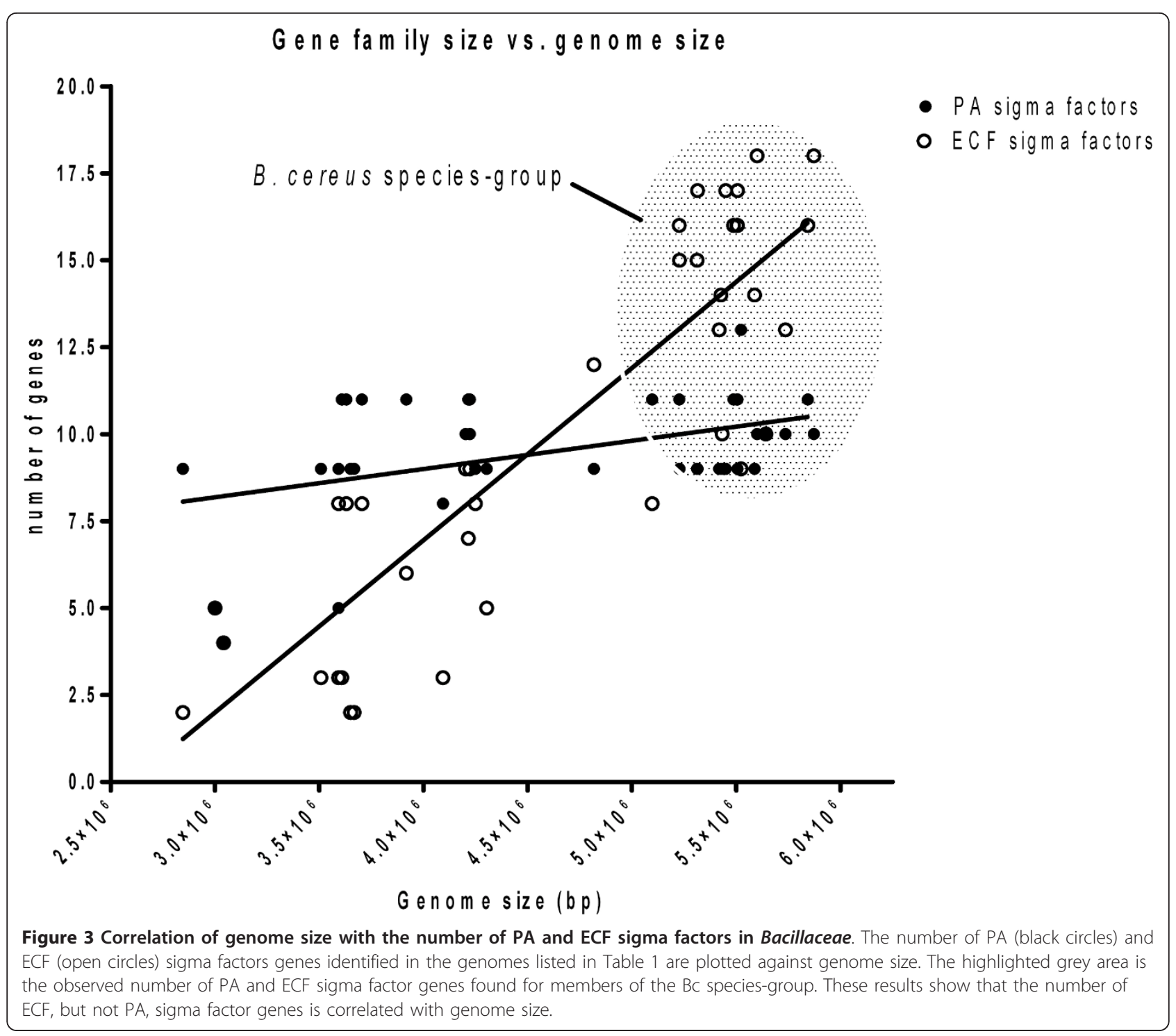

present in all Bacillus species examined). At least one of these PA sigma factors, BAS0093, the ortholog of the $B$. subtilis SigH locus, is evolutionarily conserved amongst many of the Firmicutes [51]. Further, the location of these conserved PA sigma factors within their respective genomes was syntenic between genomes. Indeed, finding a PA sigma factor that was not present in all members of the $B c$ species-group was rare (Figure 4). One B. subtilis PA sigma factor, BSU16470 (SigD), lacked an orthologous sequence in all members of the $B c$ species-group. A second PA sigma factor, BSU12560 (Xpf), was uniformly found in all $B a$ strains but only in one other $B c$ strain $(B c \mathrm{ZK})$ and in $B$. weiheinstephanensis. Two (BAS0928 and BAS3231) were absent in Bc subsp. cytotoxis. In rare cases (e.g. plasmid-borne pE33L466_0212 of $B c$ ZK, with similarity to the SigA genes of $B$. clausii and $B$. halodurans), a few PAs appear to be the result of horizontal gene transfer from organisms outside of the $B c$ species-group. However these are the only data that we found indicative of horizontal transfer, suggesting indirectly that horizontal gene transfer has not been a significant contributor to sigma factor evolution in these organisms.

The pattern of ECF sigma factor distribution was decidedly different and more complex. Of the 7 ECF sigma factors found in B. subtilis, 6 were not present in the $B c$ species-group. Thus, the divergence of the $B c$ speciesgroup from $B$. subtilis resulted in a relatively stable set of PA sigma factor genes shared by both, with a regimen of gene expansion that resulted in additional ECF sigma factors encoded in the genomes of the $B c$ species-group. Interestingly, our analyses suggest that this pattern of expansion of ECF sigma factor genes within a given lineage may independently occur in another lineage of 
Table 4 PA and ECF sigma factor counts in Bacillaceae genomes

\begin{tabular}{|c|c|c|c|c|}
\hline Genome & Locus Tag & PA & ECF & Total \\
\hline \multicolumn{5}{|l|}{ Bacillus cereus species-group: } \\
\hline B. anthracis A0248 & BAA & 11 & 16 & 27 \\
\hline B. anthracis Ames & BA & 11 & 16 & 27 \\
\hline B. anthracis Ames- 0581 & GBAA & 11 & 16 & 27 \\
\hline B. anthracis CDC 684 & BAMEG & 11 & 16 & 27 \\
\hline B. anthracis Sterne & BAS & 11 & 16 & 27 \\
\hline B. cereus biovar anthracis $\mathrm{Cl}$ & $\mathrm{BACl}$ & 9 & 13 & 22 \\
\hline B. cereus 03 BB 102 & BCA & 9 & 15 & 24 \\
\hline B. cereus $\mathrm{AH} 187$ & BCAH187 & 9 & 17 & 26 \\
\hline B. cereus AH820 & BCAH820 & 10 & 18 & 28 \\
\hline B. cereus ATCC-10987 & BCE & 9 & 14 & 23 \\
\hline B. cereus ATCC14579 & $\mathrm{BCB}$ & 9 & 10 & 19 \\
\hline B. cereus B4264 & $\mathrm{BCB}$ & 9 & 14 & 23 \\
\hline B. cereus G9842 & BCG & 10 & 13 & 23 \\
\hline B. cereus Q1 & $\mathrm{BCQ}$ & 9 & 17 & 26 \\
\hline B. cereus ZK & BCZK & 11 & 16 & 27 \\
\hline B. thuringiensis Al-Hakam & BALH & 9 & 15 & 24 \\
\hline B. thuringiensis $\mathrm{BMB} 171$ & BMB & 10 & 10 & 20 \\
\hline B. thuringiensis konkukian & BT & 9 & 17 & 26 \\
\hline B. weihenstephanensis KBAB4 & KBAB & 10 & 18 & 28 \\
\hline B. cereus cytotoxis NVH 391-98 & Bcer98 & 8 & 3 & 11 \\
\hline \multicolumn{5}{|l|}{ Bacillus subtilis group: } \\
\hline B. amyloliquefaciens FZB42 & RBAM & 11 & 6 & 17 \\
\hline B. licheniformis ATCC- 14580 & BL & 11 & 9 & 20 \\
\hline B. licheniformis DSM-13 & Bli & 10 & 9 & 19 \\
\hline B. pumilus SAFR-032 & BPUM & 11 & 8 & 19 \\
\hline B. subtilis 168 & BSU & 11 & 7 & 18 \\
\hline \multicolumn{5}{|l|}{ Bacillus megaterium: } \\
\hline B. megaterium DSM319 & BMD & 11 & 8 & 19 \\
\hline B. megaterium QM-B1551 & BMQ & 13 & 9 & 22 \\
\hline \multicolumn{5}{|l|}{ Geobacillus group: } \\
\hline Anoxybacillus flavithermus WK1 & Aflv & 9 & 2 & 11 \\
\hline Geobacillus C56-T3 & GC56T3 & 9 & 2 & 11 \\
\hline G. kaustophilus HTA426 & GK & 9 & 3 & 12 \\
\hline G. thermodenitrificans NG80-2 & GTNG & 11 & 3 & 14 \\
\hline Geobacillus WCH70 & GWCH70 & 9 & 3 & 12 \\
\hline Geobacillus Y412MC61 & GYMC61 & 9 & 2 & 11 \\
\hline \multicolumn{5}{|l|}{ Other Bacillaceae: } \\
\hline Lysinibacillus sphaericus C3-41 & Bsph & 9 & 12 & 21 \\
\hline Oceanobacillus iheyensis HTE831 & $\mathrm{OB}$ & 11 & 8 & 19 \\
\hline \multicolumn{5}{|l|}{ Bacillus halodurans group: } \\
\hline B. clausii KSM-K16 & $A B C$ & 9 & 5 & 14 \\
\hline B. halodurans C-125 & $\mathrm{BH}$ & 10 & 9 & 19 \\
\hline B. pseudofirmus OF4 & BpOF4 & 9 & 8 & 17 \\
\hline B. selenitireducens MLS10 & Bsel & 5 & 8 & 13 \\
\hline \multicolumn{5}{|l|}{ Exiguobacterium: } \\
\hline Exiguobacterium AT1b & EAT1B & 5 & 5 & 10 \\
\hline E. sibiricum 255-15 & Exig & 4 & 4 & 8 \\
\hline
\end{tabular}

Table 4 PA and ECF sigma factor counts in Bacillaceae genomes (Continued)

\begin{tabular}{lclll}
\hline Paenibacillaceae Outgroups: & & & & \\
Brevibacillus brevis NBRC-100599 & BBR & 11 & 41 & 52 \\
Paenibacillus JDR 2 & Pjdr2 & 10 & 19 & 29 \\
\hline
\end{tabular}

Bacillales. Our initial screen of sigma factors identified 52 sigma factors encoded in Brevibacillus brevis [52]. Of these 52 genes, 41 are ECF sigma factors. The B. brevis ECF sigma factor gene family may therefore represent an independent and dramatic expansion, comparing whole-genome phylogenetic analysis (see above) and the absence of sequence similarity of the B. brevis ECF sigma factors to those of the $B c$ species-group (data not shown).

In contrast to the relative conservation of the PA sigma factors, the patterns of gene duplication/loss among paralogous ECF sigma factors of the $B c$ species-group were difficult to deduce (Figure 5). No clear syntenic pattern was observed when comparing the location of these ECFs in the various genomes. Neighbor-joining (NJ) analysis (phylogenetic relationships of the $499 B c$ species-group sigma factors can be found in Additional file 4) indicates some support for relationships between four groups of $B c$ species-group ECF sigma factors, including: 1) BAS0964 and BAS2600 (supported in $70 \mathrm{NJ}$ bootstrap replicates), 2) a grouping of three paralogs including BAS2758 and BcerKBAB4-5577, followed by BAS1966 (supported in 90 and 93 NJ replicates, respectively), 3) BAS2285 and BAS0613 (supported in 83 NJ bootstrap replicates, and 4) BAS2545 and BcerKBAB4-3133 (supported in $100 \mathrm{NJ}$ replicates). However, evidence of more recent common ancestry between any pair of sigma factor paralogs is the exception rather than the rule. The remaining $18 \mathrm{Bc}$ species-group ECF sigma factor genes are of indeterminate relation to one another, and the preponderance of evidence seems to point to an active period of ECF sigma factor duplications in the ancestors of the $B c$ speciesgroup. However, the evolutionary origin of many of the ECF sigma factors in the $B c$ species-group is difficult to discern, as the phylogenetic placement of these genes was more complex than for PA sigma factors. While it was relatively unusual to find PA sigma factors that were only encoded in some genomes, the pattern of ECF sigma factor genes harbored by some but not all $B c$ species-group organisms was complex (compare Figures 4 and 5).

\section{Conclusions}

The preponderance of evidence presented here and elsewhere is that the ECF sigma factors of the $B c$ species- 
Table 5 PA sigma factor genes in the BC species-group compared to $B$. subtilis

\begin{tabular}{|c|c|c|c|c|c|c|c|c|c|c|c|c|c|c|c|c|c|c|c|c|c|c|}
\hline PA Locus tag & BAS & GBAA & $B A$ & BAA & BAMEG & BCAH820 & $\mathrm{BACl}$ & BT & BALH & BCA & BCZK & BCAH187 & BMB & BCQ & BCE & BCG & $\mathrm{BCB}$ & BC & KBAB & Bcer98 & BSU & Orthologous BSU locus tag \\
\hline BAS4194 & + & + & + & + & + & + & + & + & + & + & + & + & + & + & + & + & + & + & + & + & + & BSU25200 (SigA) \\
\hline \multirow[t]{2}{*}{ BAS0928 } & + & + & + & + & + & + & + & + & + & + & + & + & + & + & + & + & + & + & + & & + & BSU04730 (SigB) \\
\hline & & & & & & & & & & & & & & & & & & & & & + & BSU16470 (SigD) \\
\hline BAS3755 & + & + & + & + & + & + & + & + & + & + & + & + & + & + & + & + & + & + & + & + & + & BSU15320 (SigE) \\
\hline BAS3983 & + & + & + & + & + & + & + & + & + & + & + & + & + & + & + & + & + & + & + & + & + & BSU23450 (SigF) \\
\hline BAS3754 & + & + & + & + & + & + & + & + & + & + & + & + & + & + & + & + & + & + & + & + & + & BSU15330 (SigG) \\
\hline BAS0093 & + & + & + & + & + & + & + & + & + & + & + & + & + & + & + & + & + & + & + & + & + & BSU00980 (SigH) \\
\hline BAS3231 & + & + & + & + & + & + & + & + & + & + & + & + & + & + & + & + & + & + & + & & + & BSU13450 (Sigl) \\
\hline BAS4236 & + & + & + & + & + & + & + & + & + & + & + & + & + & + & + & + & + & + & + & + & + & $\begin{array}{c}\text { BSU25760, BSU26390 } \\
\text { (SigK) }\end{array}$ \\
\hline BAS3522 & + & + & + & + & + & & & & & & + & & & & & & & & + & & + & BSU12560 (Xpf) \\
\hline BAS3823 & + & + & + & + & + & & & & & & & & & & & & & & & & & \\
\hline BAS5102 & + & + & + & + & + & + & + & + & + & + & + & + & + & + & + & + & + & + & + & + & & \\
\hline Bcer98_2607 & & & & & & & & & & & & & & & & & & & & + & & \\
\hline BCG9842_0035 & & & & & & & & & & & & & & & & + & & & & & & \\
\hline BMB171_P0077 & & & & & & & & & & & + & & + & & & & & & & & & \\
\hline
\end{tabular}

A ' + ' designates the presence of a PA sigma factor ortholog group. The PA locus tag shown is from B. anthracis strain Sterne, unless this gene was not found in that organism. In those instances another locus tag was chosen as a representative. Genome abbreviations are as in Table 1. 
Table 6 ECF sigma factor genes in the $B C$ species-group compared to $B$. subtilis

\begin{tabular}{|c|c|c|c|c|c|c|c|c|c|c|c|c|c|c|c|c|c|c|c|c|c|c|}
\hline ECF Locus tag & BAS & GBAA & $B A$ & BAA & BAMEG & BCAH820 & $\mathrm{BACl}$ & BT & BALH & BCA & BCZK & BCAH187 & BMB & $\mathrm{BCQ}$ & $\mathrm{BCE}$ & BCG & $\mathrm{BCB}$ & $\mathrm{BC}$ & KBAB & Bcer98 & BSU & $\begin{array}{c}\text { Orthologous BSU locus } \\
\text { tag }\end{array}$ \\
\hline BAS0964 & + & + & + & + & + & + & + & + & + & + & + & + & + & + & + & + & + & & + & & & \\
\hline BAS2285 & + & + & + & + & + & + & + & + & + & + & + & + & + & + & & + & + & + & + & & & \\
\hline BAS3082 & + & + & + & + & + & + & + & + & & + & + & + & & + & & & & & + & & + & BSU09520 (SigM) \\
\hline BAS0171 & + & + & + & + & + & + & & & + & + & + & + & & + & + & & & & + & & & \\
\hline BAS0613 & + & + & + & + & + & + & & + & + & + & + & + & & + & + & + & + & + & + & & & \\
\hline BAS1035 & + & + & + & + & + & + & + & + & + & + & + & + & & + & + & + & + & + & + & & & \\
\hline BAS1626 & + & + & + & + & + & + & + & + & + & + & + & + & + & + & + & + & + & + & + & & & \\
\hline BAS1658 & + & + & + & + & + & + & + & + & + & + & + & + & + & + & + & + & + & + & + & & & \\
\hline BAS1966 & + & + & + & + & + & + & + & + & + & + & + & + & + & + & + & + & + & + & + & & & \\
\hline BAS2323 & + & + & + & + & + & + & + & + & + & + & + & + & + & + & + & + & + & + & + & & & \\
\hline BAS2545 & + & + & + & + & + & + & + & + & + & + & + & & & + & & & & & & & & \\
\hline BAS2600 & + & + & + & + & + & + & + & + & + & + & + & + & + & + & + & + & + & + & + & + & & \\
\hline BAS2758 & + & + & + & + & + & + & & & & & & & & & & & & & & & & \\
\hline BAS3383 & + & + & + & + & + & + & + & + & + & + & + & + & + & + & + & + & + & + & + & & & \\
\hline BAS4558 & + & + & + & + & + & + & + & & + & & + & + & & + & + & & + & & + & & & \\
\hline BAS5212 & + & + & + & + & + & + & + & + & + & + & + & + & + & + & + & + & & + & & & & \\
\hline BALH_4199 & & & & & & + & & + & + & + & & + & & + & & & & & + & & & \\
\hline BCAH187_A3458 & & & & & & & & & & & & + & & & & & & & & & & \\
\hline BCAH820_1326 & & & & & & + & & & & & & & & & & & & & & & & \\
\hline BCE_1118 & & & & & & & & & & & & & & & + & & & & & & & \\
\hline BCE_5322 & & & & & & & & & & & & & & & + & & & & & & & \\
\hline Bcer98_3970 & & & & & & & & & & & & & & & & & & & & + & & \\
\hline BcerKBAB4_3133 & & & & & & & & & & & & & + & & & + & + & & + & + & & \\
\hline BcerKBAB4_4716 & & & & & & & & + & & & & & & & & & & & + & & & \\
\hline BcerKBAB4_5577 & & & & & & & & & & & & & & & & + & & & + & & & \\
\hline BCQ_1681 & & & & & & & & + & & & + & + & & + & & & + & & + & & & \\
\hline ВT9727_0859 & & & & & & & & + & & & & & & & & & & & & & & \\
\hline
\end{tabular}




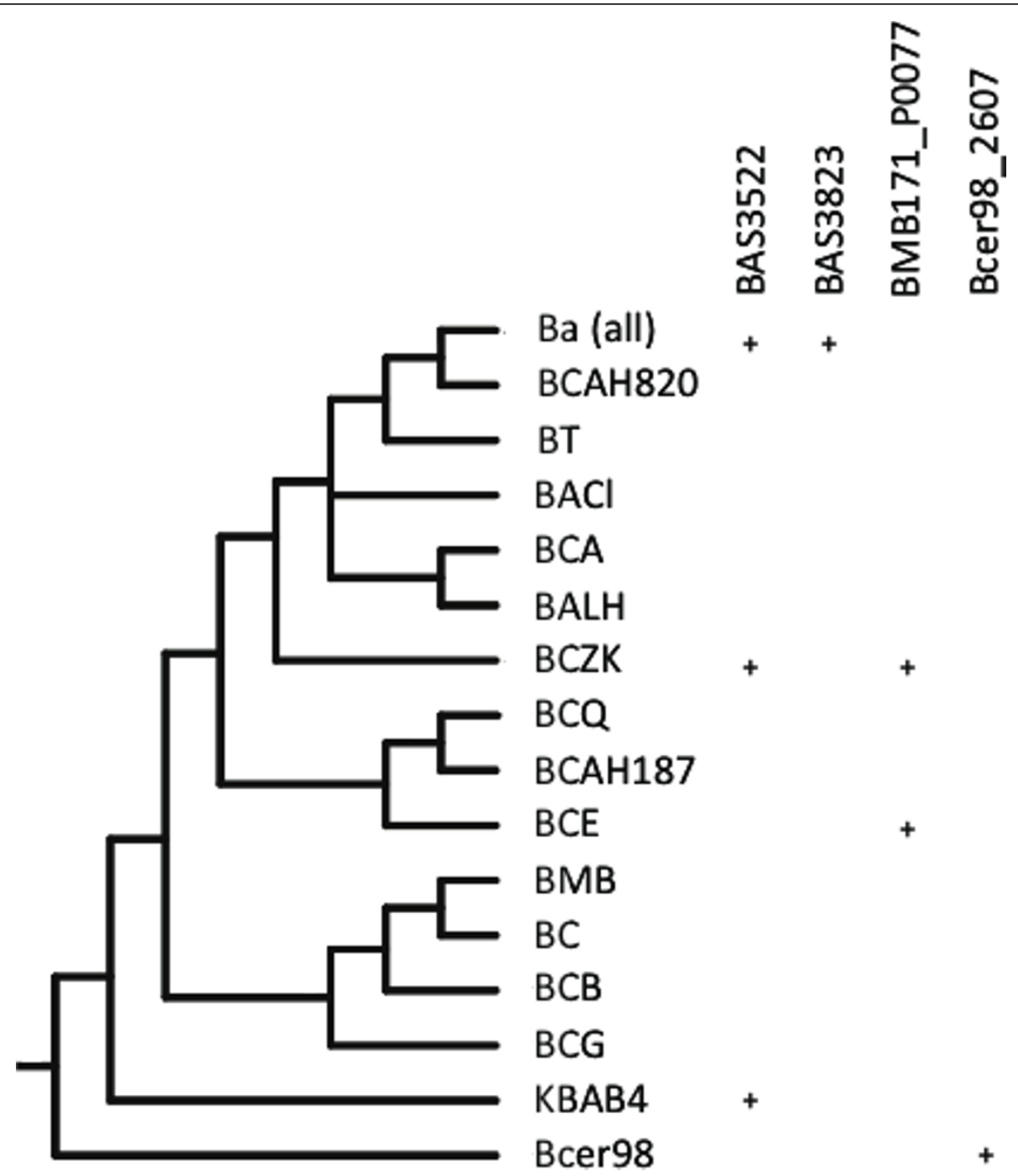

Figure 4 Phylogenetic distribution of PA sigma factors in the $B c$ species-group. Sigma factors genes found in fewer than all of the genomes listed in Table 1, mapped on a BC species-group cladeogram similar to that shown in Figure 2. The five Ba strains in Table 1 have a gene content identical to strain Ba strain Sterne, and so are condensed to one line in this tree. A + indicates the presence of a gene, as listed in the column heading, in that genome. Genome abbreviations are as found in Table 1.

group have common ancestry with one another and they are the product of gene duplications, although at this time the bulk of that evidence is raw sequence similarity. Our hypothesis is that many of the ancestors of these genes regulated a larger sub-set of genes than their descendents do presently. Following duplication, each cognate descendent sigma factor was then free to specialize (fine-tune) for a smaller subset of genes and for a more specialized role, and in the process of evolving into this specialized niche these genes then become critically important in the survival of descendent generations and are retained in their respective genomes. This subfunctionalization [53] of gene regulation also is potentially reinforced by duplication and/or specialization of the genes which they regulate, which are likewise free from constraints that arise from being co-regulated with a larger set of genes. Interestingly, this suggests that, although our ability to discern relationships among paralogous ECF sigma factors at this time is, at best, murky, in the future these relationships may be deduced from genes that each sigma factor is found to regulate.

\section{Methods}

\section{Whole-genome single copy-gene phylogeny}

Our initial aim was to determine the sigma factor content of the ancestral $B c$ species-group genome and then to determine the changes that had subsequently 


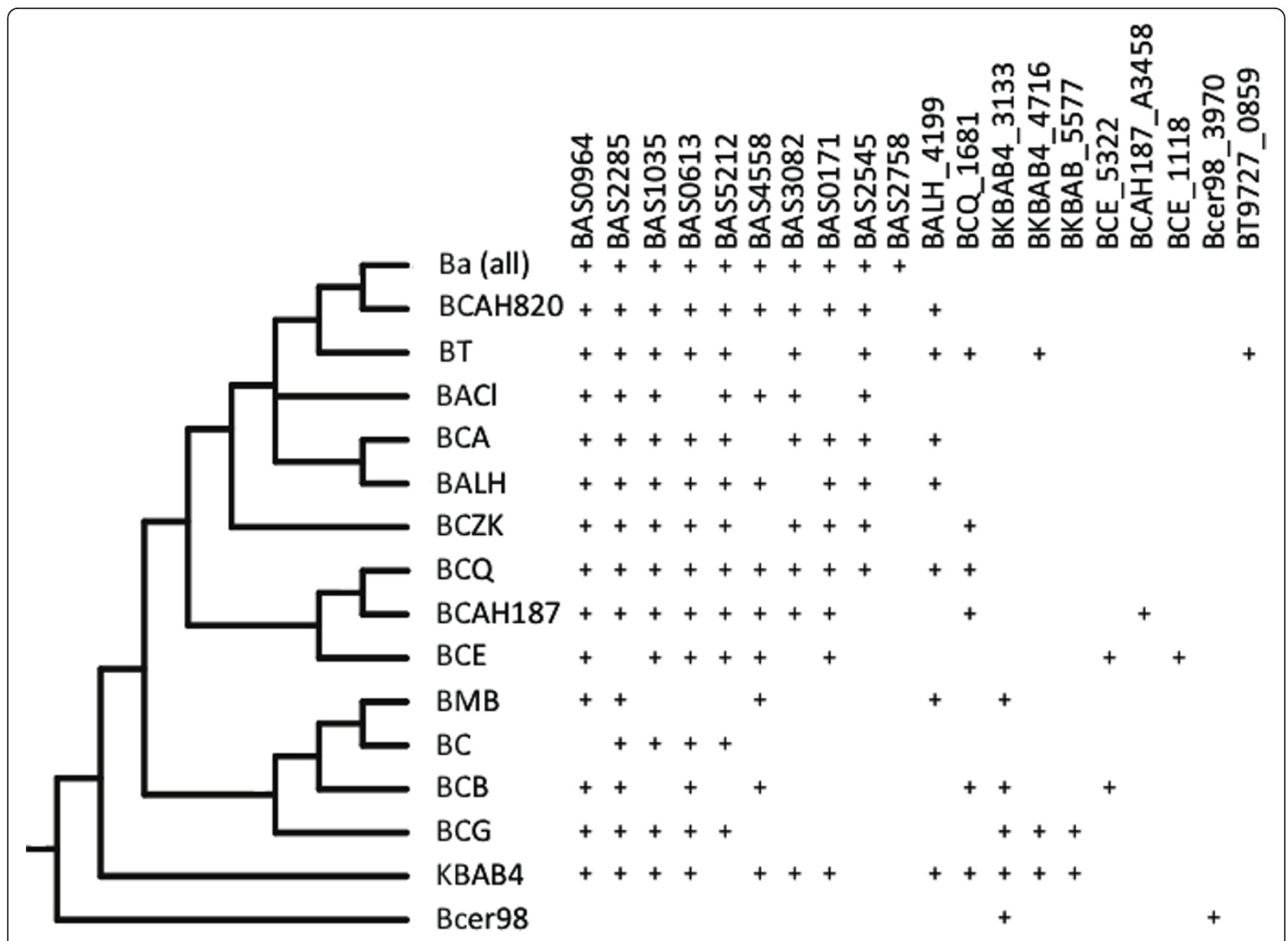

Figure 5 Phylogenetic distribution of ECF sigma factors in the BC species-group. Presentation and analyses are as described for Figure 4.

occurred during divergence of these genomes. However, the genus Bacillus has undergone numerous and complex recent taxonomic revisions and been the subject of discordant phylogenetic results $[1,43]$, making any definitive definition of the genus a potential complication. Consequently, we constructed a phylogenetic tree of the Bacillaceae that was independent of earlier efforts, but relied solely on whole genome sequences to discern relationships. Our efforts focused on the family Bacillaceae as defined by the ribosomal 16S rDNA sequences contained in the Ribosomal Database Project Release 10 [44], to direct our sampling of whole-genome data (Table 1) available at NCBI. This yielded a total dataset of 41 genomes. We purposely excluded draft genome sequences from this analysis to ensure that the absence of a given sigma factor was not an artifact of the incomplete sequence available for that organism. Two close relatives of the Bacillaceae, Paenibacillus and Brevibacillus, from the closely related family Paenibacillaceae, were used as outgroups for the purpose of rooting. We then performed phylogenetic analyses on the larger
Bacillaceae to identify the closest relatives to the $B c$ species-group.

Determination of a gene's orthology is the most important complicating factor in identifying phylogenetic relationships derived from whole genome data. We avoided this problem by restricting our analysis to single-copy genes, for which determination of orthology versus paralogy is not needed [54]. Aligned amino acid sequences were used because the extent of divergence of the genes examined made alignments of DNA sequences unreliable in many cases. Single-copy genes were identified using BLAST searches of each annotated proteincoding gene of one genome to all other genomes listed in Table 1. Results of the BLAST were parsed to identify instances where a gene's BLAST result produced a hit for one and only one of each genome in the analysis. Qualifying genes (Additional file 1) were extracted from the dataset and aligned with ClustalW [55] and put into a concatenated cumulative dataset for phylogenetic analysis with PHYLIP [56]. Phylogenetic analysis of this data set with the Proml progam of PHYLIP utilized the 
maximum-likelihood algorithm and 100 bootstrap replicates.

\section{Identification of sigma factor genes and MEME analysis} Genes encoding prospective sigma factors of the $B c$ species-group were identified with an iterative automated BLAST search of amino acid sequences, using as an initial reference the annotated sigma factors of $B$. subtilis, the most studied of Bacillus genomes. The $B$. subtilis proteins were initially compared by BLAST to the predicted protein coding sequences of the $B c$ species-group. Proteins identified in this analysis were iteratively compared by BLAST against the $B c$ speciesgroup until no additional prospective sigma factors were found. This process, while minimizing the possibility of false negative results (missed sigma factors), inevitably resulted in the inclusion of sequences that, although bearing superficial similarity to a known sigma factor, were likely not functional sigma factors (false positives). Consequently, this analysis was supplemented with MEME [57]] analysis using the zoops setting. The zoops setting does not require the presence of a motif since it is unlikely for these genes to have repeated motifs. All other MEME settings used the default parameters. We searched for up to 10 motifs, 7 of which proved informative for identifying these sigma factors, and differentiating between PA and ECF sigma factors (Tables 3 and 4 and Additional file 3). MEME motifs were utilized to segregate genes that most likely encoded functional sigma factors from those that were not. An additional benefit of the MEME analysis is that it provided independent evidence in addition to that of the BLAST analyses to segregate sigma ${ }^{70}$ PA sigma factors from ECF sigma factors. This gene identification process also was vulnerable to variation in annotations between the published genomes, which could result in the omission of sigma factors that were not present in the original annotations. Thus, we used TBLASTN searches of the identified sigma factors against the complete nucleotide sequences of all genomes, which were consequently examined to see if any such cryptic nonannotated sigma factors were present in members of the $B c$ species-group. The presence/absence data reported here was updated to reflect these gaps in the publicly-available annotations. Lastly, sigma factor proteins identified in these analyses were aligned using ClustalW and phylogenetic relations among them were examined using the neighbor-joining algorithm of Molecular Evolutionary Genetics Analysis (MEGA) [58]. Other algorithms (such as maximum-likelihood) were computationally infeasible due to the large size of the data set (499 genes).

\section{Additional material}

Additional file 1: Single-copy genes used in the phylogenetic analysis of the Bacillaceae. Annotations for each of the single-copy gene are from the Paenibacillus genome as submitted to Genbank, one of the outgroups included in the analysis.

Additional file 2: Sigma factor genes identified in this study. Locus tags for genes found in each genome follow the locus tag identifier or sigma factor identifier for each ortholog.

Additional file 3: Results of MEME analysis of the sigma factor genes identified in iterative BLAST searches. MEME results for 10 motifs (nmotifs $=10$ ) are shown, 7 of which follow phylogenetic patterns that differentiate PA from ECF sigma factors (Tables 2 and 3).

Additional file 4: Results of phylogenetic analysis of the sigma factors identified in Additional file 2. Phylogenetic analysis utilized the neighbor-joining algorithm of MEGA (see text).

\section{Acknowledgements}

We thank Michael Day and Jeremy Zaitshik for insightful discussion and comments on an earlier version of this manuscript. These studies were supported by Grant \# P20RR016478 from the National Center for Research Resources (NCRR), a component of the National Institutes of Health $(\mathrm{NIH})$. The contents of this publication are solely the responsibility of the authors and do not necessarily represent the official views of NCRR or NIH. We sadly report that, during the review of this manuscript, Timothy Schmidt unexpectedly died while at work. Tim was a good friend and colleague, and will be missed.

\section{Authors' contributions}

TS performed the data analyses included in the manuscript, except for Figures $1 \mathrm{~A} / \mathrm{B}$, which were analyzed together by TS and ES. All authors read and approved the final manuscript.

\section{Competing interests}

The authors declare that they have no competing interests.

Received: 17 February 2011 Accepted: 24 August 2011

Published: 24 August 2011

\section{References}

1. Rooney AP, Price NP, Ehrhardt C, Swezey JL, Bannan JD: Phylogeny and molecular taxonomy of the Bacillus subtilis species complex and description of Bacillus subtilis subsp. inaquosorum subsp. nov. Int J Syst Evol Microbiol 2009, 59(Pt 10):2429-2436.

2. Koehler TM: Bacillus anthracis physiology and genetics. Mol Aspects Med 2009, 30(6):386-396.

3. Hadjifrangiskou $M$, Chen $Y$, Koehler TM: The alternative sigma factor sigmaH is required for toxin gene expression by Bacillus anthracis. J Bacteriol 2007, 189(5):1874-1883.

4. Soufiane B, Cote JC: Bacillus thuringiensis Serovars bolivia, vazensis and navarrensis Meet the Description of Bacillus weihenstephanensis. Curr Microbiol 2009.

5. Helgason E, Okstad OA, Caugant DA, Johansen HA, Fouet A, Mock M, Hegna I, Kolsto AB: Bacillus anthracis, Bacillus cereus, and Bacillus thuringiensis-one species on the basis of genetic evidence. Appl Environ Microbiol 2000, 66(6):2627-2630

6. Auger S, Galleron N, Bidnenko E, Ehrlich SD, Lapidus A, Sorokin A: The genetically remote pathogenic strain NVH391-98 of the Bacillus cereus group is representative of a cluster of thermophilic strains. App/ Environ Microbiol 2008, 74(4):1276-1280

7. Lapidus A, Goltsman E, Auger S, Galleron N, Segurens B, Dossat C, Land ML, Broussolle V, Brillard J, Guinebretiere $\mathrm{MH}$, et al: Extending the Bacillus cereus group genomics to putative food-borne pathogens of different toxicity. Chem Biol Interact 2008, 171(2):236-249.

8. Stenfors Arnesen LP, Fagerlund A, Granum PE: From soil to gut: Bacillus cereus and its food poisoning toxins. FEMS Microbiol Rev 2008, 32(4):579-606. 
9. Moyer AL, Ramadan RT, Novosad BD, Astley R, Callegan MC: Bacillus cereusinduced permeability of the blood-ocular barrier during experimental endophthalmitis. Invest Ophthalmol Vis Sci 2009, 50(8):3783-3793.

10. Latsios G, Petrogiannopoulos C, Hartzoulakis G, Kondili L, Bethimouti K, Zaharof A: Liver abscess due to Bacillus cereus: a case report. Clin Microbiol Infect 2003, 9(12):1234-1237.

11. Psiachou-Leonard E, Sidi V, Tsivitanidou M, Gompakis N, Koliouskas D, Roilides E: Brain abscesses resulting from Bacillus cereus and an Aspergillus-like mold. J Pediatr Hematol Oncol 2002, 24(7):569-571.

12. Steggles JR, Wang J, Ellar DJ: Discovery of Bacillus thuringiensis virulence genes using signature-tagged mutagenesis in an insect model of septicaemia. Curr Microbiol 2006, 53(4):303-310.

13. Fedhila S, Nel P, Lereclus D: The InhA2 metalloprotease of Bacillus thuringiensis strain 407 is required for pathogenicity in insects infected via the oral route. J Bacteriol 2002, 184(12):3296-3304.

14. Wei JZ, Hale K, Carta L, Platzer E, Wong C, Fang SC, Aroian RV: Bacillus thuringiensis crystal proteins that target nematodes. Proc Natl Acad Sci USA 2003, 100(5):2760-2765.

15. Cappello M, Bungiro RD, Harrison LM, Bischof LJ, Griffitts JS, Barrows BD, Aroian RV: A purified Bacillus thuringiensis crystal protein with therapeutic activity against the hookworm parasite Ancylostoma ceylanicum. Proc Natl Acad Sci USA 2006, 103(41):15154-15159.

16. Rae R, Riebesell M, Dinkelacker I, Wang Q, Herrmann M, Weller AM, Dieterich C, Sommer RJ: Isolation of naturally associated bacteria of necromenic Pristionchus nematodes and fitness consequences. J Exp Biol 2008, 211(Pt 12):1927-1936.

17. Gunawan S, Tufts DM, Bextine BR: Molecular identification of hemolymphassociated symbiotic bacteria in red imported fire ant larvae. Curr Microbiol 2008, 57(6):575-579

18. Han CS, Xie G, Challacombe JF, Altherr MR, Bhotika SS, Brown N, Bruce D, Campbell CS, Campbell ML, Chen J, et al: Pathogenomic sequence analysis of Bacillus cereus and Bacillus thuringiensis isolates closely related to Bacillus anthracis. J Bacteriol 2006, 188(9):3382-3390.

19. Passalacqua KD, Varadarajan A, Byrd B, Bergman NH: Comparative transcriptional profiling of Bacillus cereus sensu lato strains during growth in CO2-bicarbonate and aerobic atmospheres. PLoS One 2009, 4(3):e4904.

20. Huynen MA, Bork P: Measuring genome evolution. Proc Natl Acad Sci USA 1998, 95(11):5849-5856.

21. Lozada-Chavez I, Angarica VE, Collado-Vides J, Contreras-Moreira B: The role of DNA-binding specificity in the evolution of bacterial regulatory networks. J Mol Biol 2008, 379(3):627-643.

22. Lozada-Chavez I, Janga SC, Collado-Vides J: Bacterial regulatory networks are extremely flexible in evolution. Nucleic Acids Res 2006, 34(12):3434-3445.

23. Slamti L, Lereclus D: Specificity and polymorphism of the PlcR-PapR quorum-sensing system in the Bacillus cereus group. J Bacteriol 2005, 187(3):1182-1187.

24. Mignot T, Mock M, Robichon D, Landier A, Lereclus D, Fouet A: The incompatibility between the PIcR- and AtxA-controlled regulons may have selected a nonsense mutation in Bacillus anthracis. Mol Microbiol 2001, 42(5):1189-1198.

25. Koehler TM: Bacillus anthracis genetics and virulence gene regulation. Curr Top Microbiol Immunol 2002, 271:143-164.

26. Martin J, Zhu W, Passalacqua KD, Bergman N, Borodovsky M: Bacillus anthracis genome organization in light of whole transcriptome sequencing. BMC Bioinformatics 11(Suppl 3):S10.

27. Cole ST, Eiglmeier K, Parkhill J, James KD, Thomson NR, Wheeler PR, Honore N, Garnier T, Churcher C, Harris D, et al: Massive gene decay in the leprosy bacillus. Nature 2001, 409(6823):1007-1011.

28. Anderson I, Sorokin A, Kapatral V, Reznik G, Bhattacharya A, Mikhailova N, Burd H, Joukov V, Kaznadzey D, Walunas T, et al: Comparative genome analysis of Bacillus cereus group genomes with Bacillus subtilis. FEMS Microbiol Lett 2005, 250(2):175-184.

29. Paget MS, Helmann JD: The sigma70 family of sigma factors. Genome Biol 2003, 4(1):203.

30. Helmann JD: The extracytoplasmic function (ECF) sigma factors. Adv Microb Physiol 2002, 46:47-110.

31. Mittenhuber G: A phylogenomic study of the general stress response sigma factor sigmaB of Bacillus subtilis and its regulatory proteins. $J \mathrm{Mol}$ Microbiol Biotechnol 2002, 4(4):427-452.
32. Gruber TM, Gross CA: Multiple sigma subunits and the partitioning of bacterial transcription space. Annu Rev Microbiol 2003, 57:441-466.

33. Takamatsu H, Kodama T, Imamura A, Asai K, Kobayashi K, Nakayama T, Ogasawara N, Watabe K: The Bacillus subtilis yabG gene is transcribed by Sigk RNA polymerase during sporulation, and yabG mutant spores have altered coat protein composition. J Bacteriol 2000, 182(7):1883-1888.

34. Wang ST, Setlow B, Conlon EM, Lyon JL, Imamura D, Sato T, Setlow P, Losick R, Eichenberger P: The forespore line of gene expression in Bacillus subtilis. J Mol Biol 2006, 358(1):16-37.

35. Miyazaki $H$, Kato H, Nakazawa T, Tsuda M: A positive regulatory gene, pvdS, for expression of pyoverdin biosynthetic genes in Pseudomonas aeruginosa PAO. Mol Gen Genet 1995, 248(1):17-24.

36. Agnoli K, Lowe CA, Farmer KL, Husnain SI, Thomas MS: The ornibactin biosynthesis and transport genes of Burkholderia cenocepacia are regulated by an extracytoplasmic function sigma factor which is a part of the Fur regulon. J Bacteriol 2006, 188(10):3631-3644.

37. Dona V, Rodrigue S, Dainese E, Palu G, Gaudreau L, Manganelli R, Provvedi R: Evidence of complex transcriptional, translational, and posttranslational regulation of the extracytoplasmic function sigma factor sigmaE in Mycobacterium tuberculosis. J Bacteriol 2008, 190(17):5963-5971.

38. Llamas MA, van der Sar A, Chu BC, Sparrius M, Vogel HJ, Bitter W: A Novel extracytoplasmic function (ECF) sigma factor regulates virulence in Pseudomonas aeruginosa. PLoS Pathog 2009, 5(9):e1000572.

39. Kazmierczak MJ, Wiedmann M, Boor KJ: Alternative sigma factors and their roles in bacterial virulence. Microbiol Mol Biol Rev 2005, 69(4):527-543.

40. Staron A, Sofia HJ, Dietrich S, Ulrich LE, Liesegang H, Mascher T: The third pillar of bacterial signal transduction: classification of the extracytoplasmic function (ECF) sigma factor protein family. Mol Microbiol 2009, 74(3):557-581.

41. Helmann JD, Chamberlin MJ: Structure and function of bacterial sigma factors. Annu Rev Biochem 1988, 57:839-872.

42. Keynan Y, Weber G, Sprecher H: Molecular identification of Exiguobacterium acetylicum as the aetiological agent of bacteraemia. $J$ Med Microbiol 2007, 56(Pt 4):563-564.

43. Xu D, Cote JC: Phylogenetic relationships between Bacillus species and related genera inferred from comparison of $3^{\prime}$ end 165 rDNA and $5^{\prime}$ end 16S-23S ITS nucleotide sequences. Int I Syst Evol Microbiol 2003, 53(Pt 3):695-704.

44. Cole JR, Wang Q, Cardenas E, Fish J, Chai B, Farris RJ, Kulam-SyedMohideen AS, McGarrell DM, Marsh T, Garrity GM, et al: The Ribosomal Database Project: improved alignments and new tools for rRNA analysis. Nucleic Acids Res 2009, , 37 Database: D141-145.

45. Alcaraz LD, Moreno-Hagelsieb G, Eguiarte LE, Souza V, Herrera-Estrella L, Olmedo-Alvarez G: Understanding the evolutionary relationships and major traits of Bacillus through comparative genomics. BMC Genomics 11(1):332.

46. Tourasse NJ, Helgason E, Klevan A, Sylvestre P, Moya M, Haustant M, Okstad OA, Fouet A, Mock M, Kolsto AB: Extended and global phylogenetic view of the Bacillus cereus group population by combination of MLST, AFLP, and MLEE genotyping data. Food Microbiol 28(2):236-244

47. Helgason E, Tourasse NJ, Meisal R, Caugant DA, Kolsto AB: Multilocus sequence typing scheme for bacteria of the Bacillus cereus group. Appl Environ Microbiol 2004, 70(1):191-201.

48. Lechner S, Mayr R, Francis KP, Pruss BM, Kaplan T, Wiessner-Gunkel E, Stewart GS, Scherer S: Bacillus weihenstephanensis sp. nov. is a new psychrotolerant species of the Bacillus cereus group. Int I Syst Bacteriol 1998, 48(Pt 4):1373-1382.

49. Nakamura LK: Bacillus pseudomycoides sp. nov. Int I Syst Bacteriol 1998, 48(Pt 3):1031-1035.

50. Lonetto M, Gribskov M, Gross CA: The sigma 70 family: sequence conservation and evolutionary relationships. J Bacteriol 1992, 174(12):3843-3849

51. Morikawa K, Inose $\mathrm{Y}$, Okamura H, Maruyama A, Hayashi H, Takeyasu K, Ohta T: A new staphylococcal sigma factor in the conserved gene cassette: functional significance and implication for the evolutionary processes. Genes Cells 2003, 8(8):699-712.

52. Yamada H, Tsukagoshi N, Udaka S: Morphological alterations of cell wall concomitant with protein release in a protein-producing bacterium, Bacillus brevis 47. J Bacteriol 1981, 148(1):322-332. 
53. Lynch $M$, Force $A$ : The probability of duplicate gene preservation by subfunctionalization. Genetics 2000, 154(1):459-473.

54. Daubin V, Gouy M, Perriere G: A phylogenomic approach to bacterial phylogeny: evidence of a core of genes sharing a common history. Genome Res 2002, 12(7):1080-1090.

55. Thompson JD, Higgins DG, Gibson TJ: CLUSTAL W: improving the sensitivity of progressive multiple sequence alignment through sequence weighting, position-specific gap penalties and weight matrix choice. Nucleic Acids Res 1994, 22(22):4673-4680.

56. Felsenstein J: Evolutionary trees from DNA sequences: a maximum likelihood approach. J Mol Evol 1981, 17(6):368-376.

57. Bailey TL, Williams N, Misleh C, Li WW: MEME: discovering and analyzing DNA and protein sequence motifs. Nucleic Acids Res 2006, , 34 Web Server: W369-373.

58. Tamura K, Dudley J, Nei M, Kumar S: MEGA4: Molecular Evolutionary Genetics Analysis (MEGA) software version 4.0. Mol Biol Evol 2007, 24(8):1596-1599.

doi:10.1186/1471-2164-12-430

Cite this article as: Schmidt et al:: Whole-genome phylogenies of the family Bacillaceae and expansion of the sigma factor gene family in the Bacillus cereus species-group. BMC Genomics 2011 12:430.

\section{Submit your next manuscript to BioMed Central} and take full advantage of:

- Convenient online submission

- Thorough peer review

- No space constraints or color figure charges

- Immediate publication on acceptance

- Inclusion in PubMed, CAS, Scopus and Google Scholar

- Research which is freely available for redistribution

Submit your manuscript at www.biomedcentral.com/submit 